\title{
Instruir, aprender ou comunicar: Reflexão sobre os fundamentos das opções pedagógicas perspetivadas a partir do ato de ensinar
}

\author{
Instruct, learn or communicate: Reflection about the \\ foundations of pedagogical options envisaged from the \\ act of teaching
}

\author{
Rui Trindade, Ariana Cosme*
}

Universidade do Porto, Porto, Portugal

\section{Resumo}

Este é um texto por meio do qual se visa abordar os projetos de educação escolar, do ponto de vista dos seus pressupostos e implicações pedagógicas, a partir de uma abordagem que encontra na noção de paradigma o instrumento de organização de uma tal reflexão. Trata-se de uma decisão que visa definir a escala deste empreendimento, através do qual se pretende refletir sobre as crenças e as conceções de caráter ontológico e epistemológico que fundamentam os diferentes tipos de opções subjacentes aos distintos modos de conceber o ato de ensinar, enquanto ato que, segundo Roldão (2009), permite identificar e caraterizar a

RT: Doutor em Ciência da Educação, e-mail: trindade@fpce.up.pt

AC: Doutor em Ciência da Educação, e-mail: ariana@fpce.up.pt 
atividade educativa, específica e singular, dos professores nas salas de aula. Neste trabalho, e de acordo com os pressupostos acabados de enunciar, partimos do princípio que o ato de ensinar pode ser captado, hoje, em função de três paradigmas: o paradigma pedagógico da instrução, o paradigma pedagógico da aprendizagem e o paradigma pedagógico da comunicação (TRINDADE \& COSME, 2010). Três paradigmas que serão objeto de interpelação neste artigo, na medida em que exprimem três modos distintos de pensar o que se entende por educar nas escolas e, concomitantemente, a relação entre docentes, alunos e o património de informações, instrumentos, procedimentos e atitudes que foram culturalmente validados e que são considerados necessários à vida de cada um nas sociedades em que vivemos.

Palavras-chave: Pedagogia. Instrução. Ensino. Aprendizagem. Atividade docente.

\begin{abstract}
This is a text that intends to discuss school education projects from the point of view of its assumptions and pedagogical implications. We start from the notion of paradigm to state what we want to do: reflect on the beliefs and ontological and epistemological conceptions that underlie the different types of options underlying the different ways of conceiving the act of teaching, which is understood, according to Roldão (2009), as an act that identify and characterize the educational, specific and singular activity of teachers in a classroom. In this paper such act will be discussed according to three paradigms: instruction paradigm, learning paradigm and communication paradigm (TRINDADE \& COSME, 2010). The three paradigms that will be the interpellation object of this text because they express three different ways of thinking about what is meant by education in schools and, concomitantly, the relationship between teachers, students and the patrimony of information, instruments, procedures and attitudes that were culturally validated and are required to the life of each of us in the societies in which we live.
\end{abstract}

Keywords: Pedagogy. Teaching. Instruction. Learning. Teachers activity. 


\section{Introdução}

O objetivo da reflexão que mobilizou a escrita deste artigo circunscreve-se à abordagem dos discursos por meio dos quais se balizam as diferentes visões que nos revelam os princípios, os valores e os compromissos fundadores os quais contribuem para compreender e esclarecer a natureza, os significados e as implicações das estratégias e dos procedimentos curriculares, pedagógicos e didáticos, perspetivados a partir do ato de ensinar.

Trata-se de uma abordagem que entende este ato como um ato complexo, ideologicamente comprometido e epistemologicamente balizado, recusando-se assim, a qualquer leitura tecnocrática das ações educativas que têm lugar nas escolas, a qual circunscreve a importância de tais ações à avaliação, apenas, da alegada eficácia das mesmas. Ensinar é, contudo, um ato que poderá ser concebido e operacionalizado de modos diversos e por razões distintas quanto aos fundamentos, às intenções e aos pressupostos que o sustentam. Daí que seja necessário discutir o debate sobre as finalidades da Escola e, subsequentemente, sobre o que se espera o que os alunos e o professores façam e sejam nesta instituição, bem como sobre a interação que se poderá estabelecer entre os atores educativos por via da relação que estes estabelecem com o património de informações, instrumentos, procedimentos e atitudes culturalmente validado e entendido como socialmente necessário à vida de todos e de cada um nas sociedades em que vivemos. Um património que, neste trabalho, passará a ser designado, doravante e apenas, como património cultural dito comum, o qual é, para nós, o fator que justifica a existência das escolas, de qualquer escola, como espaços de socialização cultural decisivos no mundo e nas sociedades em que vivemos, assumindo-se, deste modo, como um referente incontornável do trabalho aí produzido por docentes e discentes.

Com a reflexão que pretendemos promover sobre o ato de ensinar não se pretende desvalorizar ou negligenciar o papel dos alunos como participantes do projeto de formação que lhes diz respeito, mas tão 
somente afirmar que um tal papel, independentemente do modo como é concebido, é algo que não poderá ser dissociado do modo como os professores se percecionam e atuam como docentes. Daí a opção anunciada que decorre de um pressuposto prévio, o de que é necessário conferir visibilidade ao trabalho dos professores como docentes e às intenções que subjazem a um tal trabalho, na medida em que a perda de centralidade do professor na sala de aula, reivindicada como condição necessária à afirmação do protagonismo discente, não poderá contribuir para legitimar qualquer perspetiva que contribua para desvalorizar ou, pelo menos, subvalorizar aquele trabalho. Assim sendo, este é um texto que visa reabilitar a reflexão sobre o trabalho docente no quadro mais amplo da reflexão pedagógica sobre os atos de ensinar e de aprender, tendo em conta que é o modo como se concebe e se operacionaliza o primeiro desses atos que influencia a dinâmica e a possibilidade de ocorrência do segundo.

\section{O paradigma da instrução: Ensinar é instruir}

A conceção através da qual se defende que ensinar é instruir não poderá ser dissociada da emergência e afirmação do modelo de educação escolar que teve lugar, na Europa, nos séculos XVIII e XIX, quando ocorre o movimento transnacional de escolarização das sociedades que, ao ser dinamizado pelo Estado, conduz a que a Escola passe a ser considerada como um contexto de formação de massas imprescindível à manutenção da ordem política e social que emerge sob os auspícios da Modernidade (BARROSO, 1995; SILVA, 1997; NÓVOA \& SCHRIEWER, 2000). Inaugura-se, assim, uma ruptura com os modelos de socialização até aí vigentes quando se passa a defender a necessidade de criar uma instituição especializada para educar as gerações mais jovens que contribuísse para a "reforma da humanidade" (MATOS, 1999, p. 80), a qual deveria ocorrer, de acordo com essa crença, através da "iluminação do espírito, pela instrução" (idem). 
Havendo motivações diversas que poderão explicar as afirmações locais daquele movimento transnacional de escolarização das sociedades, importa neste momento, reconhecer, apenas, que a Escola se afirmou, no tempo histórico relacionado com a sua génese, como uma instituição que, segundo Trindade e Cosme (2010, p. 18):

visava garantir a homogeneização cultural e política de uma comunidade, em função da qual se tornasse possível, num primeiro momento, construir a ideia de Nação, coletivo de indivíduos que tendem a partilhar uma identidade e um território comuns, assegurando, assim e por esta via, quer a aceitação e a apropriação das novas modalidades de controlo social e político, conformes à matriz civilizacional do projeto da Modernidade, quer, de forma articulada com tal propósito, assegurando, também, a subordinação dos indivíduos ao primado da Razão, o que permitiria aceitar a crença de que é possível tanto aceder ao saber verdadeiro, como aceitar, sem se interpelar, a existência "a priori» desse tipo de saber. Deste modo, legitimar-se-ia o direito, e o dever, de dizer aos outros, privados desse saber, aquilo que deveriam fazer, como comportar-se, que fins deveriam perseguir e que meios poderiam utilizar para cumprir tal objetivo (Magalhães, 1998).

É de acordo com este projeto que Vincent, Lahire e Thin (1994) caraterizam a «forma escolar» como o modelo educativo subjacente à afirmação da Escola como instituição educativa tutelada pelo Estado que não só mandata agentes especializados para assumirem o papel de educadores como prescreve o trabalho destes quer através de planos de estudo, determinados de forma prévia e descontextualizada, quer através de uma organização criteriosa tanto daquele espaço como do tempo de trabalho que naquela instituição tem lugar. Foi por via da estandartização curricular e da adoção de estratégias de homogeneização pedagógica cujos resultados se garantiam através de um programa de avaliação que se assumia como a finalidade do trabalho educativo a realizar, que se pode compreender o vínculo entre a génese do modelo de educação escolar e o "paradigma pedagógico da instrução" (TRINDADE \& COSME, 2010, p. 28). Um paradigma que em consonância com aquele modelo tende a sustentar uma 
conceção de ensino "que entende o ver-fazer e o ouvir como condições suficientes para se concretizar o ato de aprender, dissociando-se, assim, o momento em que se aprende do momento em que se faz, porque, mais do que aprender uma prática, se aprende, sobretudo, um conjunto de informações sobre essa prática" (idem, p. 19).

Segundo Canário (1999), o modelo de educação escolar, sob a égide do paradigma da instrução, carateriza-se por desvalorizar a experiência e os saberes dos alunos como fatores potenciadores de educação, o que, segundo o mesmo autor, se explica pelo facto de um tal projeto de educação se desenvolver em função de uma lógica educativa que se constrói a partir de duas ideias nucleares: a de que o trabalho dos professores se constrói em função da ignorância dos alunos e a de que a dinâmica da produção de conhecimentos na Escola resulta de "um processo de cumulatividade, em que a lógica do armazenar e repetir informações se sobrepõe à lógica de produção de saber" (idem, p. 3).

É tendo em conta estes pressupostos que Trindade e Cosme (2010) defendem que a aceitação do paradigma da instrução corresponde a uma conceção de educação que nos mostra estarmos perante uma dimensão eminentemente prescritiva do ato educativo que se constrói em função de "um clima de relacionamento pedagógico subordinado à afirmação do magistercentrismo como modalidade reguladora do processo de reprodução do saber" (idem, p. 30).

De acordo com um tal paradigma, e segundo Bruner (2000), os professores limitam-se a expor a informação na sua versão final, esperando que os alunos a reproduzam de forma o mais fiel possível. Para apoiar um tal processo, os docentes poderão, ainda, ilustrar essa informação com alguns exemplos que julguem ser esclarecedores para que, no fim do processo, acabem por confrontar os alunos com exercícios através dos quais estes possam ter oportunidade de mostrarem aquilo que aprenderam. Afirma-se, por esta via, o que Fabre (1999) designa por proposicionalismo escolar onde são as respostas, mais do que as perguntas dos alunos, que se valorizam, sobretudo, quando estes se mostram capazes de reproduzir o que se considera ser as respostas verdadeiras. Se o proposicionalismo 
escolar se define em termos curriculares e pedagógicos como um desafio educativo circunscrito são, contudo, os seus fundamentos epistemológico que merecem ser desvendados, já que, por via de uma tal opção, se exprime uma conceção concreta do saber a partir do qual se defende que o saber desvenda a realidade tal qual ela é,

na medida em que esta tende a ser concebida como uma entidade preexistente às leituras que produzimos sobre a mesma. Daí que não seja por acaso que, neste âmbito, os saberes declarativos tendam a ser entendidos como saberes hegemônicos e a instrução seja assumida, por isso, como modalidade exclusiva de ação pedagógica (TRINDADE \& COSME, 2010, p. 32).

É perante este quadro concetual que se explica a sedução exercida pelo paradigma da instrução, já que este propõe

uma modalidade de intervenção educativa que tanto permite sustentar a crença de que basta ensinar bem para que alguém possa aprender como permite, igualmente, que aqueles que ensinam possam sentir-se seguros sobre a tarefa que têm de concretizar, visto que se especifica, de forma clara e inequívoca, aquilo que se pretende que os alunos aprendam (idem, p. 32).

É este conjunto de crenças que sustenta uma alegada e desejada omnipotência pedagógica dos professores, a qual constitui, hoje, um problema que somos obrigados a enfrentar, e a discutir, pelo modo como influencia a configuração da identidade profissional docente.

Numa Escola que deixou de entender o insucesso escolar como expressão do sucesso político e social da mesma (GRÁCIO, 1995), — porque os processos de estratificação social que se constroem a partir da instituição escolar afirmam-se através de dinâmicas curriculares e pedagógicas em que a exclusão deixou de ser a dimensão de referência de tais processos —, tal omnipotência só poderá ser entendida hoje como um obstáculo que impede os professores de responderem aos desafios profissionais que têm de enfrentar em escolas que se caraterizam quer pela heterogeneidade do 
seu corpo discente quer pelas ambições educativas que manifestam, quando nestas escolas se valoriza a dimensão inclusiva dos projetos de educação escolar como um objetivo a perseguir. Independentemente da distância que, neste caso, se verifica existir entre o dizer e o fazer curricular e pedagógico, é importante valorizar, mesmo assim, a tensão acima enunciada porque a resolução de uma tal tensão, ou a própria tentativa de a enfrentar, acaba, pelo menos, por perturbar a crença na omnipotência profissional dos professores e de repensar a sua atividade profissional em função de outros parâmetro concetuais e praxeológicos.

\section{O paradigma pedagógico da aprendizagem: Ensinar é promover o desenvolvimento de competências cognitivas e relacionais}

"A emergência do paradigma pedagógico da aprendizagem" (TRINDADE \& COSME, 2010, p. 41 ) explica-se em função da recusa do paradigma da instrução, sendo os discursos e as propostas de ação pedagógica do Movimento da Escola Nova a componente mais visível e decisiva dessa recusa (TRINDADE, 2013). Havendo outros contributos a considerar na configuração do paradigma da aprendizagem, foi este movimento e os pedagogos que com ele são identificados, como, entre outros, Ferrière, Claparède, Montessori, Decroly ou mesmo Dewey, que definiram os fundamentos sobre os quais assenta este paradigma.

Trata-se de um paradigma que, como já o referimos, se começa por definir em oposição ao paradigma da instrução, denunciando e recusando:
a) o estatuto de menorização a que a Escola sujeita os seus alunos;
b) a normatividade e a unicidade metodológica em vigor nesse campo;
c) os programas de estudos estandartizados e geridos de forma burocrática;
d) as limitações da instrução como modo de formação (TRINDADE \& COSME, 2010, p. 41).


Ou seja, é a recusa de uma Escola que se oriente em função de tais princípios que explica a defesa e aceitação do conjunto de eixos invariantes sobre os quais assenta o paradigma da aprendizagem, nomeadamente o facto de se considerar os alunos como o centro de gravidade dos projetos de educação escolar e a adoção de dispositivos de mediação pedagógica que permitam valorizar quer as suas aprendizagens quer a recusa das intenções e das ações instrutivas dos professores.

Se coube ao Movimento da Escola Nova o papel pioneiro na construção e divulgação do paradigma da aprendizagem, importa reconhecer, igualmente, o papel da corrente cognitivista, que na área da Psicologia, contribuiu, igualmente, para a legitimação deste paradigma. Trata-se de uma relação cuja génese radica na crença matricial de que a educação deverá respeitar a natureza da criança (CLAPARÈDE, 1931; FERRIÈRE, 1934) e no facto do Movimento da Escola Nova recorrer à Psicologia para revelar publicamente essa natureza e, deste modo, indicar "ao educador o caminho a seguir e os métodos a utilizar” (COUSINET, 1945, p. 41). Em suma, e:

ao contrário do paradigma da instrução que entende ser possível confirmar a existência de aprendizagens sempre que um aluno é capaz de reproduzir informação, exercícios e gestos, no paradigma da aprendizagem entende-se, pelo contrário, que o ato de aprender se encontra mais relacionado com o desenvolvimento de competências cognitivas e relacionais do que com a apropriação de conteúdos construídos por outros. Deste modo, aprende-se quando somos estimulados a pensar e a aprender a aprender, porque, nesta abordagem, é o desenvolvimento cognitivo dos sujeitos e das dinâmicas endógenas que lhe estão subjacentes que poderão garantir a ocorrência de aprendizagens (TRINDADE \& COSME, 2010, p. 44).

É este vínculo entre o paradigma da aprendizagem e a abordagem cognitivista que contribui para explicar a importância das dinâmicas e dos processos internos de mediação cognitiva como fatores determinantes da atividade humana, o que explica a crença de que os indivíduos 
são, mais do que recetores de informação que outros construíram, processadores dessa mesma informação, cabendo à Escola, por isso, proporcionar-lhes as oportunidades educativas que favoreçam a possibilidade dos alunos aprenderem a realizar um tal processamento.

Esta é uma leitura que acaba por encontrar na obra de Piaget uma boa parte dos seus fundamentos epistemológicos quer um contributo para "elucidar os processos funcionais que sustentam o processo de desenvolvimento cognitivo dos indivíduos" (idem, p. 46). Trata-se de um autor que, a partir de uma reflexão epistemológica singular sobre o que se entende por conhecer e como é que se constrói o conhecimento, contribui para reabilitar o sujeito que aprende como ator educativo ainda que tenda a menorizar, como objeto de reflexão, o património de informações, instrumentos, procedimentos e atitudes culturalmente validado que é necessário a qualquer processo de construção do saber. O problema com que a obra de Piaget nos confronta e, em geral, o paradigma da aprendizagem tem a ver com uma proposta através da qual se afirma um aluno que é caraterizado como um ser culturalmente autossuficiente. Não se podendo afirmar, de acordo com este paradigma, que a Escola não desafia os alunos, pode-se inferir, no entanto, que tais desafios são, essencialmente, desafios que visam suscitar, sobretudo, o desenvolvimento das competências cognitivas e relacionais dos sujeitos.

De acordo com um tal quadro gnoseológico o papel dos professores é objeto de discursos que se pautam por uma razoável ambiguidade, ainda que seja o papel de facilitador de aprendizagens que parece ser a definição mais consensual, o que se explica pelo facto da preocupação maior do paradigma da aprendizagem ter a ver com a possibilidade das crianças aprenderem de forma autónoma, o que, na ausência de uma reflexão sobre as tensões epistemológicas com que essas mesmas crianças se irão defrontar no decurso das suas aprendizagens que deverão realizar, nos coloca perante uma série de problemas que não poderão ser ignorados. Problemas estes que nos remetem para 
uma opção, pois é de uma opção que se trata, cuja principal vulnerabilidade tem a ver com o facto do estatuto pedagógico do património cultural, que constitui um dos principais fatores de legitimação da existência da Escola, não ser objeto de valorização e de interpelação explícita, ainda que seja referido como uma variável a ter em conta, mesmo que de forma abstracta e indiferenciada. A relação com este património é uma relação que, deste modo, é abordada em função, sobretudo, dos mecanismos de natureza psicológica que o sujeito é capaz de ativar. Tem-se em conta, assim, as particularidades dos aprendentes, mas não se valoriza, de forma explícita e como uma questão crucial, as particularidades epistemológicas e conceptuais da informação e dos objetos de estudo, o que constitui a referência do trabalho de aprendizagem dos alunos. Mais do que a informação, enfatiza-se a necessidade dos sujeitos desenvolverem competências que lhes permitam processá-la, através do desenvolvimento e da utilização de estratégias universais de abordagem, organização, avaliação e utilização dessa informação. Neste sentido, pode afirmar-se que se estabelece uma relação de equivalência entre as atividades de processamento da informação e as aprendizagens escolares propriamente ditas (TRINDADE \& COSME, 2010, p. 55-56).

Assim, e ao contrário do paradigma da instrução para quem os alunos eram uma espécie de tábua rasa e o saber era visto como um produto que se adquire, no paradigma da aprendizagem esses mesmos alunos são caraterizados como detentores de teorias mais ou menos coerentes sobre o mundo, as quais poderão adquirir coerência e pertinência à medida que aqueles forem encorajados a partilhá-las e a discuti-las uns com os outros (BRUNER, 2000). Deste modo, a função dos professores é, sobretudo, a de promoverem "o desenvolvimento de intercâmbios subjetivos" (idem, p. 85), o que nos mostra uma preocupação pela construção de um modelo pedagógico mutualista, o qual se interessa, sobretudo, pela interpretação e compreensão da realidade, mais do que pelo acesso e apropriação à perfeição do conhecimento factual (idem). 
Até que ponto é possível e interessante dissociar o investimento na compreensão e interpretação dos factos dos instrumentos e dispositivos culturais que permitem concretizar um tal investimento?

Porque esta é uma questão que não se discute no âmbito do paradigma da aprendizagem, ainda que seja uma questão decisiva e incontornável para se repensar a Escola em função de outros parâmetros educativos, é que propusemos um terceiro paradigma, o da comunicação, que, afirmando a necessidade de serem as aprendizagens dos alunos a preocupação maior da Escola, aborda esta problemática a partir de pressupostos concetuais distintos daqueles que sustentam o paradigma da aprendizagem. Daí que o paradigma da comunicação contribua para configurar os estatutos e os papéis de professores e alunos a partir de uma leitura dos mesmos distinta daquelas que os paradigmas anteriores propõem, o que, em larga medida, se explica por via da reflexão que, sob a égide daquele paradigma, se produz sobre a relação dos alunos com o que temos vindo a designar por património de informações, instrumentos, procedimentos e atitudes culturalmente validado e entendido como socialmente pertinente. É uma tal relação com este tipo de património cultural que explica que a ação docente seja pensada e se concretize de uma forma diferente daquelas que os outros paradigmas balizaram.

\section{O paradigma pedagógico da comunicação: Educar é contribuir para as aprendizagens dos alunos através da proposta de desafios culturais}

O "paradigma pedagógico da comunicação" (Trindade \& Cosme, 2010, p. 58) é um paradigma que se distancia tanto do paradigma da aprendizagem como do paradigma da instrução.

Numa tentativa de clarificar as razões de um tal distanciamento começamos por considerar que enquanto o paradigma da instrução e o paradigma da aprendizagem se fixam num dos polos da relação - o do património cultural a difundir, no caso do primeiro, e os alunos, no caso do segundo, o paradigma da comunicação interessa-se, sobretudo, pela 
gestão da relação que se estabelece entre aqueles dois polos, o que implica que tenha em conta quer as singularidades dos sujeitos em formação e as suas possibilidades quer que construa uma reflexão explícita sobre o estatuto daquele património que, dada a sua importância social, constitui o objeto de referência do trabalho educativo que se desenvolve na Escola. É a partir desta clarificação concetual que se pode compreender melhor a proposta de caraterização deste paradigma que propusemos (idem), onde defendemos que:

Chamaremos paradigma da comunicação a este paradigma pedagógico que se caracteriza por valorizar a qualidade dos mais variados tipos de interações que acontecem numa sala de aula como fator potenciador das aprendizagens dos alunos que, neste caso, são entendidas em função do processo de apropriação, por parte destes, de uma fatia decisiva do património cultural disponível, enquanto condição do processo de afirmação e desenvolvimento pessoal e social das crianças e dos jovens no seio da sociedade em que vivemos (Trindade \& Cosme, 2010, p. 59).

Como se constata, para este paradigma, a ocorrência das aprendizagens dos alunos, vinculadas ao seu desenvolvimento pessoal e social, depende da qualidade da comunicação que aqueles estabelecem entre si e com os seus professores, em função da necessidade de se apropriarem de informações entendidas como necessárias, da utilização de instrumentos materiais e concetuais cuja pertinência decorre das exigências e dos desafios para os quais são convocados, por via das experiências a que são chamados a viver no mundo em que habitam, e da necessidade de desenvolverem um conjunto de competências e atitudes decorrentes do facto de participarem em sociedades diversas, plurais e contraditórias que se desejam mais democráticas e que se caraterizam, igualmente, como sociedades do conhecimento.

É a partir deste conjunto de pressupostos que se pode compreender melhor as razões que explicam o distanciamento do paradigma da comunicação face ao paradigma da instrução, o que pode ser descrito em função do modo como ambos os paradigmas entendem o que é ser aluno 
e como é que definem o estatuto do que temos vindo a designar por património cultural dito comum, enquanto fator educativo de referência dos projetos de educação escolar. São questões que se encontram articuladas entre si na medida em que a desvalorização dos alunos como protagonistas do processo de ensino e de aprendizagem que lhes diz respeito decorre do facto de se entender que aquele património é uma entidade tão nuclear quanto inquestionável para o paradigma da instrução. Para este paradigma seria o contato com um tal património que permitiria libertar os alunos da sua alegada ignorância e incompetência, uma missão que caberia aos professores assumir, os quais seriam mandatados, por isso, para assumirem, como instrutores, o principal papel na Escola, transformada, por via daqueles pressupostos, na "instância do «dar lições» (de ciência, de conhecimento); a instância do informar (passar conteúdos sob a forma de regras, fatos ou conhecimentos) e a instância do "advertir» (que recobre o duplo sentido do prevenir e o de fazer sentir a sua posição)" (MATOS, 1999, p. 82).

A distância do paradigma da comunicação face ao paradigma da aprendizagem explica-se por outras razões que não têm tanto a ver com a desvalorização dos alunos como protagonistas mas com o modo como ambos os paradigmas acabam por definir um tal protagonismo. Uma problemática que nos conduz a discutir como os referidos paradigmas abordam o contributo do que tem vindo a ser designado por património cultural dito comum para o desenvolvimento dos projetos de educação escolar e da formação dos alunos no seio das escolas. Neste sentido, a distância entre os paradigmas que estamos a discutir decorre do facto de, no paradigma da comunicação, se entender, na direção concetual apontada por Bruner (2000), que é necessário "resgatar a cultura do seu papel de variável dependente do desenvolvimento psicológico dos indivíduos, para lhe outorgar, pelo contrário, um papel nuclear" (TRINDADE \& COSME, 2010, p. 64) no âmbito do processo educativo vivido por cada sujeito que, na perspetiva de Bruner, depende do facto dos significados que atribuímos às coisas, conferindo-lhes existência, serem construídos no interior 
da mente, mas terem origem e adquirirem sentido no seio da cultura que os gerou (BRUNER, 2000).

Assim e tal como defendem Trindade e Cosme (2010, p. 64):

a realidade externa existe, mas só pode ser conhecida pelas propriedades da mente e pelos sistemas simbólicos que se ativam para captar essa realidade e, de algum modo, para a construir. Trata-se de uma perspetiva que se vê reforçada pela reflexão de B. Rogoff, quando esta afirma que concebe o desenvolvimento pessoal de um sujeito como algo que ocorre em consonância com a sua participação "em atividades socioculturais contínuas, as quais se modificam, elas próprias, com o envolvimento de indivíduos em sucessivas gerações" (Rogoff, 2005, p. 44), recusando, assim, que os processos tendentes a promover o desenvolvimento pessoal e o desenvolvimento social sejam entendidos "«como se» existissem independentemente uns dos outros" (obra citada, p. 46). Isto é, segundo Rogoff, na "perspetiva sociocultural emergente, a cultura não é uma entidade que influencia os indivíduos. Em lugar disso, as pessoas contribuem para a criação de pessoas. Dessa forma, os processos individuais e culturais são mutuamente constitutivos, e não definidos separadamente" (idem, p. 51).

É a partir desta abordagem que se compreende porque é que as aprendizagens deixam de ser identificadas com o "desenvolvimento de intercâmbios subjetivos" (BRUNER, 2000, p. 85), tal como se propõe no paradigma da aprendizagem, para serem vistas como expressão da "gestão do conhecimento "objetivo»" (idem, p. 90), o que significa que no paradigma da comunicação se defende, na linha da reflexão proposta por Bruner (idem), que:

as intervenções educativas no seio das escolas devem ajudar os alunos quer a captar a distinção entre o conhecimento pessoal e aquilo que é tido por conhecido pela cultura, quer a apropriar-se do modo como este tipo de conhecimento foi sendo construído (TRINDADE \& COSME, 2010, p. 65). 
Partindo desta explanação teórica pode afirmar-se que o confronto entre o paradigma da comunicação e o paradigma da aprendizagem deverá ser compreendido a partir do processo de interpelação teórica a que foi submetido o espaço concetual que o cognitivismo balizou, em função do qual se estabeleceu um

processo de distanciamento conceptual e epistemológico que esteve na origem da emergência de um campo que, apesar da partilhar algumas das orientações teóricas nucleares do cognitivismo, não deixa de propor um quadro teórico distinto cujas implicações se fazem sentir em diferentes espaços, nomeadamente ao nível da reflexão sobre os atos de educar e de aprender. É em torno da valorização da cultura como fator que afeta de forma decisiva quer as aprendizagens dos alunos, quer, sobretudo, o seu desenvolvimento cognitivo e, em geral, o seu desenvolvimento pessoal e social que se afirma o movimento teórico que Bruner designa por Psicologia Cultural (Bruner, 2000; 2002a). Um movimento através do qual o psicólogo americano recusa a abordagem computacionalista da mente humana (Bruner, 2000), enquanto abordagem que contribuiu para formatar, na área da Psicologia, o paradigma cognitivista clássico, de forma a afirmar, em alternativa, o que ele designa por perspetiva culturalista (idem). Uma perspetiva que se constrói em torno de uma conceção nuclear, a de que a mente humana se constitui à medida que se utiliza e se usufrui da cultura humana, em função da qual a mente deixa de ser concebida como um dispositivo informático e a atividade cognitiva deixa de ser entendida em função, somente, dos mecanismos psicológicos que se ativam para que os sujeitos se possam assumir como processadores de informação. Trata-se de um posicionamento teórico que, de algum modo, expressa a influência de Vygotsky nesta fase da reflexão produzida por Bruner, nomeadamente quando, para além da importância decisiva que atribui aos processos de interação entre os sujeitos como variável psicológica incontornável (Vygotsky, 1987, 1978; 1987; 1998), propõe uma conceção de desenvolvimento cognitivo, a que Bruner (2000, 2002a) atribui uma centralidade inequívoca, que rompe com a representação de que estamos perante um processo eminentemente intrapsíquico, afirmando, antes, o desenvolvimento como um processo de natureza cultural que se constrói a partir das trocas, da partilha e da cooperação 
que as interações entre os sujeitos e, igualmente, entre estes e os instrumentos de mediação instrumental potenciam (TRINDADE \& COSME, 2010, p. 62-63).

É tendo em conta, então, o enquadramento concetual delineado que se poderá compreender, enfim, que o distanciamento que temos vindo a abordar deriva do fato de o paradigma da aprendizagem "fazer depender as aprendizagens do processo de desenvolvimento cognitivo que as potencia, enquanto o paradigma da comunicação entende que o ato de aprender pode acontecer quando os alunos se envolvem na construção de saberes" (idem, p. 62). Um processo que, sob a inspiração de Monteil (1985), definimos como um confronto que se estabelece entre a informação construída por outros e o conhecimento pessoal daqueles alunos, o qual condiciona as suas possibilidades de abordar e interpretar tal informação. Sendo este um pressuposto, aparentemente, aceitável também para o paradigma da aprendizagem importa referir, no entanto, que, para este paradigma, um tal processo tende a ser abordado em função das dinâmicas intrapsíquicas ativadas pelos sujeito em formação (PIAGET, 1978; 1993), enquanto que, para o paradigma da comunicação, tais dinâmicas passam de condição subordinante a condição subordinada de um processo que se define mais pela sua dimensão cultural do que pela sua dimensão psicológica.

É esta desvalorização da dimensão cultural, por parte do paradigma da aprendizagem, subsequente à focalização nas competências cognitivas e relacionais dos sujeitos como fatores primeiros das aprendizagens a realizar, que se explica porque, neste paradigma, os sujeitos tendem a ser vistos, tal como atrás já o afirmamos, como seres culturalmente autossuficientes. No paradigma da comunicação esta é, contudo, uma possibilidade que se recusa, já que se se reconhece que ninguém aprende por nós também se reconhece que ninguém aprende sozinho (COSME \& TRINDADE, 2013). Aprendemos porque somos compelidos a fazê-lo num mundo que tanto nos obriga a ir para além das nossas «predisposições naturais» (BRUNER, 2000; CHARLOT, 2000) como coloca ao nosso dispor 
o estojo de ferramentas (ideias, instrumentos, procedimentos, valores) que a humanidade foi construindo para poder responder aos desafios com que foi sendo confrontada ao longo da sua história. São essas ferramentas que constituem, para as novas gerações, um objeto de apropriação obrigatório, na medida em que é a partir de tais ferramentas que os seus membros se tornarão capazes de atribuir significados ao mundo onde vivem, produzir novos significados acerca deste mundo e ampliar as suas possibilidades de intervenção no âmbito do mesmo. É que segundo Bruner (2000), “o desenvolvimento terá que ser compreendido em função quer dos constrangimentos intrínsecos, resultantes da nossa evolução como espécie, quer dos constrangimentos impostos pelos sistemas simbólicos que permitem potenciar a capacidade humana de interpretar significados e de construir realidades" (TRINDADE \& COSME, 2010, p.72), o que implica que se considere que

se a “«realidade» que imputamos aos «mundos» que habitamos é construída" (Bruner, 2000, p.40), a educação deve contribuir, por isso, para que se aprenda a utilizar os instrumentos de produção de significados e de construção da realidade. Um propósito que conduz a reconhecer, por um lado, que o significado que se atribui a qualquer facto, proposição ou interação se constrói em função de um determinado quadro de referências, a partir do qual esse significado é definido e, por outro, que esse não é um processo que se constrói arbitrariamente ou de forma linear e homogénea, já que é marcado tanto pelas experiências pessoais dos sujeitos como pelos padrões culturais que influenciaram essas experiências e as interpretações que estes produzem face às mesmas (idem, p. 72-73).

De acordo com esta abordagem, aprender é visto como um processo paradoxal porque, em primeiro lugar, se ninguém aprende por nós, o que temos que aprender não é, contudo, produto exclusivo da nossa vontade e potencialidades. Em segundo lugar, importa compreender que os desafios relacionados com a aprendizagem confrontam os sujeitos em formação com o desconhecido, o que implica que um tal confronto para além de ser uma decisão que, por vezes, transcende estes mesmos sujeitos 
é um confronto que obriga a processos de interlocução cultural com outros, naquele momento mais capazes e experientes, cuja função é a de não só proporcionarem as condições que são necessárias para a realização das aprendizagens como, igualmente, a de oferecerem àqueles sujeitos a possibilidade de constatarem a existência de objetos de saber que poderão vir a ser, ou não, os objetos de referência das suas aprendizagens.

Em suma, para o paradigma da comunicação, o protagonismo dos sujeitos é possível e, sobretudo, é necessário ainda que se defina de forma diferente daquele que é proposto pelo paradigma da aprendizagem. Em rigor, este protagonismo trata-se mais de um co-protagonismo porque depende do modo como os outros o potenciam, apoiando, discutindo, desafiando, propondo, discordando, confrontando e avaliando as atividades, do ponto de vista dos procedimentos e dos produtos que se dinamizaram e construíram para que tais atividades suscitassem as aprendizagens dos alunos.

É a partir desta premissa que o papel do professor adquire outros contornos, já que não podendo ser visto como um instrutor também não poderá ser identificado, apenas, com o papel de facilitador. Ariana Cosme (2009) chama-lhe interlocutor qualificado e com esta afirmação não pretende mais do que reconhecer que as intenções educativas dos professores, o modo de pensar e organizar o seu trabalho, a forma como planifica e concebe a atividade dos alunos na sala de aula ou o modo como reflete e operacionaliza o processo de avaliação neste âmbito, são fatores determinantes para que os alunos sejam entendidos como protagonistas de um projeto de formação que é também o seu. Daí que, tendo em conta o propósito anunciado com a redação deste trabalho, o qual consistia em promover uma reflexão sobre os fundamentos das opções pedagógicas perspetivadas a partir do ato de ensinar, a função do professor seja a de promover um projeto de comunicação que já não podendo garantir as aprendizagens dos alunos deverá garantir, todavia, as condições que permitam a ocorrência destas mesmas aprendizagens. daí que seja este projeto de comunicação e o modo como o professor o dinamiza que, na 
nossa opinião, constitui uma das problemáticas mais pertinentes da reflexão pedagógica que teremos que empreender.

\section{Referências}

BARROSO, J. Os liceus: Organização pedagógica e administração (1836 - 1960) Vol. I. Lisboa: Fundação Calouste Gulbenkian e Junta Nacional de Investigação Científica e Tecnológica, 1995.

BRUNER, J. Cultura da educação. Lisboa: Edições 70, 2000.

CANÁRIO, R. Educação de Adultos: Um campo e uma problemática. Lisboa: Educa - Formação, 1999.

CHARLOT, B. Da relação com o saber: Elementos para uma teoria. Porto Alegria: Artes Médicas, 2000.

CLAPARÈDE, É. L'Éducation fonctionelle. Neuchatel: Delachaux \& Niestlé, S.A., 1931.

COUSINET, Roger. Une méthode de travail libre par groupes. Les Éditions du Cerf, 1945

COSME, A; TRINDADE, R. Organização e gestão do trabalho pedagógico : perspetivas, questões, desafios e respostas. Porto: LivPsic, 2013.

FABRE, M. Situations-problèmes et savoir scolaire. Paris: P.U.F. 1999.

FERRIÈRE, A. A escola activa. Porto: Editora Educação Nacional, 1934

GRÁCIO, R. Obra Completa I. Lisboa: Fundação Calouste Gulbenkian, 1995.

NÓVOA, A.; SCHRIEWER, J. A difusão mundial da escola. Lisboa: Educa, 2000.

MATOS, M. S. Teorias e práticas da formação: Contributo para a reabilitação do trabalho pedagógico. Porto: Edições ASA, 1999. 
MONTEIL, J-M. Dynamique sociale et systèmes de formation. Paris: Éd. Universitaires - UNMFREO, 1985

PIAGET, J. Seis estudos de psicologia. Lisboa: Publicações D. Quixote., 1978.

PIAGET, J; INHELDER, B. A psicologia da criança. Porto: Edições ASA, 1993.

ROLDÃO, M. C. Estratégias de ensino: o saber e o agir do professor. Gaia: Fundação Manuel Leão, 2009.

SILVA, T. T. da. O adeus às metanarrativas educacionais. In: Silva, T.T. da (Org.), O sujeito da educação: Estudos foucaultianos. Rio de Janeiro: Vozes, 1997. p. $247-258$

TRINDADE, R.; COSME, A. Escola, educação e aprendizagem: Desafios e respostas pedagógicas. Rio de Janeiro: WAK editora, 2010.

TRINDADE, R. O Movimento da Educação Nova e a reinvenção da Escola: Da afirmação de uma necessidade aos equívocos de um desejo. Porto: Universidade Porto Editorial, 2013.

VINCENT, G.; LAHIRE, B.; THIN, D. Sur l' histoire et la théorie de la forme scolaire. In: VINCENT, GUY (Coord.), L' éducation prisonnière de la forme scolaire?: Scolarisation et socialisation dans les societés industrielles. Lyon: Presses Universitaires de Lyon, 1994, p. 207-227.

Recebido: 20/01/2016

Received: 01/20/2016

Aprovado: 10/03/2016

Approved: 03/10/2016 